\title{
PROPAGAÇÃO DO UMEZEIRO (Prunus mume Sieb \& Zucc.) POR ESTAQUIA HERBÁCEA ${ }^{1}$
}

\author{
NEWTON ALEX MAYER²; FERNANDO MENDES PEREIRA³; JAIR COSTA NACHTIGAL ${ }^{4}$
}

\begin{abstract}
RESUMO - A utilização do umezeiro ou damasqueiro-japonês (Prunus mume Sieb \& Zucc.) como porta-enxerto de Prunus sp. vem despertando grande interesse em função de sua rusticidade, resistência a pragas e doenças, adaptação e, principalmente, por reduzir o porte de pessegueiros e nectarineiras. Este trabalho foi conduzido no Departamento de Produção Vegetal da FCAV/UNESP, Câmpus de Jaboticabal-SP, e teve por objetivo estudar a propagação vegetativa desta espécie. Para tanto, utilizaram-se estacas herbáceas com $12 \mathrm{~cm}$ de comprimento dos Clones 02; 05; 10 e 15, provenientes do Programa de Melhoramento Genético do Instituto Agronômico de Campinas, submetidas às concentrações de 0 e $2000 \mathrm{mg}^{-L^{-1}}$ de AIB, por cinco segundos. O experimento foi conduzido em delineamento experimental inteiramente casualizado, com 4 repetições de 20 estacas por parcela, esquema fatorial $4 \times 2$, sendo o fator clone em 4 níveis (Clones $02 ; 05 ; 10$ e 15) e AIB em 2 níveis ( 0 e 2000 mg. $\left.\mathrm{L}^{-1}\right)$. De acordo com os resultados, verificou-se diferença entre os clones quanto à porcentagem de enraizamento, sendo o Clone 15 significativamente superior ao Clone 02 (93,75\% e 78,13\%, respectivamente). Os Clones 05 (85,0\%) e $10(83,13 \%)$ comportaram-se como intermediários, não diferindo dos demais. Não houve diferença entre os clones testados quanto à formação de calo, raízes por estaca, comprimento de raízes e porcentagem de estacas brotadas. O ácido indolbutírico na concentração de $2000 \mathrm{mg} . \mathrm{L}^{-1}$ favoreceu a emissão de raízes adventícias e aumentou o comprimento das raízes, mas não teve influência na brotação das estacas. Não houve efeito da interação entre os fatores testados para as variáveis analisadas.
\end{abstract}

Termos de indexação: enraizamento, porta-enxerto, ácido indolbutírico.

\section{PROPAGATION OF JAPANESE APRICOT (Prunus mume Sieb \& Zucc.) BY HERBACEOUS CUTTINGS}

\begin{abstract}
The use of the japanese apricot (Prunus mume Sieb \& Zucc.) as rootstock of Prunus sp. has raised a great interest due to its rusticity, resistance to plagues and diseases, adaptation and mainly for reducing the peach and nectarines trees scales. This essay was carried out at the Department of Vegetable Production of the FCAV/UNESP, Jaboticabal Campus, São Paulo State, Brazil, with the purpose of studying the vegetative propagation of this specie. It has been used herbaceous cuttings with $12 \mathrm{~cm}$ of length originating from the Clones $02,05,10$ and 15 . These clones have been obtained at the Program of Genetic Improvement of the Instituto Agronômico de Campinas, Brazil. The herbaceous cuttings have been submitted to the following concentrations of indolbutiric acid 0 and $2000 \mathrm{mg} . \mathrm{L}^{-1}$ by five seconds. The experiment was conducted in a completely randomized design with 4 repetitions of 20 cuttings by replication, with a 4 levels clone factor $\left(02,05,10\right.$ and 15 clone) and 2 IBA levels ( 0 and $\left.2000 \mathrm{mg} . \mathrm{L}^{-1}\right)$. According to the results, it has been detected significantly difference between the clones in relation to the rooting percentage. The Clone 15 has developed a rooting percentage significantly higher than the Clone $02(93,75 \%$ and $78,13 \%$, respectively). The Clones $05(85,0 \%)$ and $10(83,13 \%)$ have showed an average performance and not differed from the others. There was no difference between the clones tested in relation to the callus formation, root per cutting, length of root and percentage of sprouted cuttings. The acid indolbutiric at the concentration of $2000 \mathrm{mg} . \mathrm{L}^{-1}$ had a beneficial effect over the rooting of the cuttings. It has favored the emission of adventitious roots and it has increased the length of the roots. However it hasn't influenced the sprouted of the cuttings. It hasn't been detected interaction between the factors tested for the analyzed variables.
\end{abstract}

Index terms: rooting, rootstock, indolbutiric acid.

\section{INTRODUÇÃo}

O damasqueiro-japonês, mais conhecido como umezeiro (Prunus mume Sieb \& Zucc.), é uma rosácea de folhas caducas, arbórea, originária da China Continental e típica de clima temperado. Seu cultivo é amplo nos países asiáticos, destacando- se o Japão e Taiwan, que o cultivam desde o século XIV (Campo Dall'Orto et al., 1998).

Seus frutos, de elevado amargor, acidez e aroma característico, são comumente utilizados pelos povos orientais no preparo de conservas - o "umeboshi" e de um licor especial o "umeshu", além de geléias e doces em massa, podendo

\footnotetext{
1 (Trabalho 259/2000). Recebido: 24/11/2000. Aceito para publicação: 28/08/2001. Parte da dissertação apresentada pelo primeiro autor, para obtenção do título de Mestre em Agronomia, Área de Concentração em Produção Vegetal, pela Faculdade de Ciências Agrárias e Veterinárias (FCAV/UNESP), Jaboticabal-SP. Apoio financeiro: FCAV/UNESP - Câmpus de Jaboticabal e CAPES.

2 Eng. Agr., M.Sc., Doutorando em Agronomia, Depto. de Produção Vegetal, FCAV/UNESP - Via de Acesso Paulo Donato Castellane Km 05 s/n, CEP 14870-000, Jaboticabal-SP. e-mail: namayer@fcav.unesp.br

3 Eng. Agr., Professor Titular Doutor, Depto. de Produção Vegetal, FCAV/UNESP, Câmpus de Jaboticabal.

4 Eng. Agr., Dr., Embrapa-CNPUV, Estação Experimental de Jales-SP. Caixa Postal 241, CEP 15700-000, Jales-SP.
} 
inclusive ser misturados às geléias de pêssego ou ameixa, conferindo-lhes mais aroma, sabor, acidez e consistência. As flores são utilizadas na ornamentação, com sentido místico e festivo (Campo Dall'Orto et al., 1995/1998).

Em função dos seus costumes, a colônia japonesa do Estado de São Paulo sempre procurou produzir o umê, resultando em repetidos fracassos por utilizarem materiais muito exigentes em frio, oriundos do Japão.

O maior interesse por esta frutífera deu-se por volta de 1970, em Botucatu, SP, quando obtiveram algumas colheitas de um material originário, provavelmente, da cultivar Koume (umê pequeno) de Taiwan, caracterizado pela baixa exigência em frio e, possivelmente, pertencente à variedade botânica Mycrocarpa. A partir daí, sua difusão no Estado de São Paulo vem sendo crescente (Campo Dall'Orto et al., 1998).

O umezeiro apresenta características agronômicas importantes, como rusticidade, sanidade de plantas, adaptação ao inverno brando e produtividade, sendo que algumas seleções do IAC atingem 100kg/planta (Campo Dall'Orto et al., 1995/1998). Mais recentemente, o umezeiro vem despertando grande interesse na fruticultura intensiva devido à possibilidade de ser utilizado como porta-enxerto para pessegueiro e nectarineira, sendo compatível com esta espécie e conferindo-lhe uma diminuição no vigor das plantas, o que possibilitaria a formação de pomares em alta densidade (Campo Dall'Orto et al., 1992 e 1994; Nakamura et al., 1999).

Além destas vantagens, a utilização do umezeiro como porta-enxerto de pessegueiro pode possibilitar a produção de frutos com maior massa e teor de sólidos solúveis, realçando a pigmentação vermelha da película, quando comparados aos frutos produzidos pelas mesmas copas enxertadas sobre a cv. 'Okinawa', tradicionalmente utilizada como porta-enxerto no Estado de São Paulo (Campo Dall'Orto et al., 1994).

A propagação vegetativa de frutíferas é uma prática extremamente importante na manutenção dos caracteres da planta-matriz. Segundo Fachinello et al. (1995), o processo de formação de raízes é afetado por fatores internos (condição fisiológica e idade da planta-matriz, tipo de estaca, época do ano, balanço hormonal, entre outros) e externos (como a temperatura, luz, umidade, substrato e condicionamento).

A capacidade de enraizamento de estacas lenhosas diretamente no campo foi estudada por Reighard et al. (1990), onde avaliaram 406 diferentes acessos de Prunus em 4 anos consecutivos, incluindo diferentes espécies, cultivares e híbridos. Os autores concluíram que o umezeiro, juntamente com amendoeiras, ameixeiras americanas, damasqueiros e Prunus fenzliana apresentaram as menores sobrevivências, entre $2 \mathrm{e}$ $9 \%$. Miranda et al. (2000) obtiveram 67,5\% de enraizamento com estacas lenhosas, utilizando o solo como substrato. Com a técnica da micropropagação, Harada \& Murai (1996) observaram que o umezeiro apresentou taxas de sobrevivência relativamente baixas na aclimatação sob nebulização intermitente, variando de 20 a $30 \%$. No caso da propagação por estaquia herbácea do umezeiro no Brasil, Nachtigal et al. (1999) obtiveram 37,95\% de enraizamento, quando as estacas foram tratadas com AIB a 2000mg. $\mathrm{L}^{-1}$.

O presente trabalho teve como objetivo estudar a viabilidade da propagação vegetativa do umezeiro por estacas herbáceas em câmara de nebulização, verificando o enraizamento de clones promissores para posterior utilização como portaenxerto de Prunus sp.

\section{MATERIAIS E MÉTODOS}

O experimento foi conduzido em câmara de nebulização intermitente, pertencente ao Departamento de Produção Vegetal da Faculdade de Ciências Agrárias e Veterinárias-UNESP, Câmpus de Jaboticabal-SP.

Plantas-matrizes dos Clones $02 ; 05 ; 10$ e 15 , provenientes do Programa de Melhoramento Genético do Instituto Agronômico de Campinas (IAC), foram mantidas em vasos plásticos sob ripado, com $50 \%$ de sombreamento. Estes clones apresentam boas características para serem utilizados como portaenxerto, especialmente por induzirem redução no porte das plantas.

As estacas foram preparadas com $12 \mathrm{~cm}$ de comprimento, diâmetro variando de 27 a $35 \mathrm{~mm}$, com 3 a 5 folhas, sendo eliminadas as folhas da parte basal. Após o preparo, as estacas foram tratadas com solução fungicida (Benomil a $0,5 \%$ p.c.) por 10 segundos. Metade do lote das estacas foi tratada com solução líquida de ácido indolbutírico (AIB) a 2000mg.L $\mathrm{L}^{-1}$, por 5 segundos, sendo que a outra metade não foi tratada. As estacas foram acondicionadas em caixas plásticas perfuradas $(37,5 \times 27 \times 9,5 \mathrm{~cm})$, contendo vermiculita de grânulos médios como substrato. As caixas plásticas foram mantidas em câmara de nebulização intermitente, por um período de 60 dias ( 17 de setembro a $16 \mathrm{de}$ novembro de 1999). O sistema de nebulização foi controlado por um "timer" programado para ligar o sistema por 5 segundos, deixando-o desligado por 40 segundos, de forma a manter uma fina película de água sobre a superfície das folhas.

$\mathrm{O}$ experimento foi conduzido em delineamento experimental inteiramente casualizado, esquema fatorial $4 \times 2$, sendo os níveis constituídos de quatro clones (Clones 02; 05; 10 e 15) e duas concentrações de AIB ( 0 e $\left.2000 \mathrm{mg} . \mathrm{L}^{-1}\right)$, com quatro repetições e 20 estacas por parcela. As variáveis analisadas foram porcentagem de estacas enraizadas, porcentagem de estacas com calo, número de raízes por estaca, comprimento das cinco maiores raízes e porcentagem de estacas brotadas. Os dados originais das variáveis expressas em porcentagem foram transformados para Arco-Seno $\sqrt{P / 100}$. Os dados foram submetidos à análise de variância, pelo teste $\mathrm{F}$, e as médias comparadas pelo teste de Tukey, ao nível de $5 \%$ de probabilidade.

\section{RESULTADOS E DISCUSSÃO}

Pelos resultados obtidos (Tabela 1), observa-se que existe diferença significativa entre o Clone 15 e o Clone 02 na porcentagem de estacas enraizadas $(93,75$ e 78,13\%, respectivamente). Os Clones 05 e 10 comportaram-se como intermediários, apresentando 85,0 e $83,13 \%$ de enraizamento, respectivamente, não diferindo estatisticamente dos anteriores. Estes dados comprovam a viabilidade da propagação vegetativa do umezeiro por meio de estacas herbáceas e estão de acordo com Nachtigal et al. (1999), que também verificaram melhores resultados no Clone 15 ao enraizamento, embora não diferindo significativamente dos demais. Vale ressaltar que os percentuais 
TABELA 1- Resposta de quatro clones de umezeiro propagados por estacas herbáceas em câmara de nebulização intermitente. Jaboticabal-SP, novembro de 1999.

\begin{tabular}{cccccc}
\hline Clone & $\begin{array}{c}\text { Estacas } \\
\text { encizadas } \\
(\%)\end{array}$ & $\begin{array}{c}\text { Estacas apenas } \\
\text { com calo } \\
(\%)\end{array}$ & $\begin{array}{c}\text { Raízes por } \\
\text { estaca }\end{array}$ & $\begin{array}{c}\text { Comprimento } \\
\text { de raízes } \\
(\mathrm{cm})\end{array}$ & $\begin{array}{c}\text { Estacas } \\
\text { brotadas } \\
(\%)\end{array}$ \\
\hline 02 & $78,13 \mathrm{~b}$ & $9,38 \mathrm{a}$ & $7,82 \mathrm{a}$ & $7,22 \mathrm{a}$ & $85,63 \mathrm{a}$ \\
05 & $85,00 \mathrm{ab}$ & $6,25 \mathrm{a}$ & $6,71 \mathrm{a}$ & $7,43 \mathrm{a}$ & $81,25 \mathrm{a}$ \\
10 & $83,13 \mathrm{ab}$ & $8,13 \mathrm{a}$ & $7,51 \mathrm{a}$ & $8,13 \mathrm{a}$ & $85,63 \mathrm{a}$ \\
15 & $93,75 \mathrm{a}$ & $4,38 \mathrm{a}$ & $7,15 \mathrm{a}$ & $8,37 \mathrm{a}$ & $87,50 \mathrm{a}$ \\
\hline F clone & $3,827^{*}$ & $1,236^{\mathrm{ns}}$ & $0,491^{\mathrm{ns}}$ & $1,770^{\mathrm{ns}}$ & $0,758^{\mathrm{ns}}$ \\
C V $(\%)$ & 11,84 & 51,29 & 26,39 & 15,06 & 11,36
\end{tabular}

Médias seguidas por letras distintas, na mesma coluna, diferem significativamente entre si, pelo teste de Tukey, ao nível de 5\% de probabilidade.

* significativo ao nível de $5 \%$ de probabilidade; ${ }^{\text {ns }}$ não significativo.

TABELA 2 - Efeito do ácido indolbutírico na propagação vegetativa do umezeiro por estacas herbáceas em câmara de nebulização intermitente. Jaboticabal-SP, novembro de 1999.

\begin{tabular}{|c|c|c|c|c|c|}
\hline 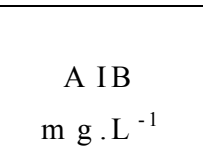 & $\begin{array}{c}\text { Estacas } \\
\text { enraizad a s } \\
(\%)\end{array}$ & $\begin{array}{c}\text { Estacas apenas } \\
\text { com calo } \\
(\%)\end{array}$ & $\begin{array}{c}\text { Raízes por } \\
\text { estaca }\end{array}$ & $\begin{array}{c}\text { Comprimento } \\
\text { de raízes } \\
(\mathrm{cm})\end{array}$ & $\begin{array}{c}\text { Estacas } \\
\text { brotad as } \\
(\%)\end{array}$ \\
\hline 0 & $78,13 \mathrm{~b}$ & 13,44 a & $3,32 \quad b$ & $7,30 \mathrm{~b}$ & 85,63 a \\
\hline 2000 & 91,88 a & $0,63 \quad b$ & 11,28 a & $8,27 \mathrm{a}$ & 84,38 a \\
\hline $\mathrm{F}_{\mathrm{A} \text { IB }}$ & $18,384 * *$ & $79,608 * *$ & $136,404 * *$ & $5,532 *$ & $0,481^{\mathrm{ns}}$ \\
\hline $\mathrm{F}$ Clone $\times$ A IB & $2,369^{\mathrm{ns}}$ & $1,025^{\mathrm{ns}}$ & $1,269^{\mathrm{ns}}$ & $1,502^{\mathrm{ns}}$ & $2,224^{\mathrm{ns}}$ \\
\hline $\mathrm{CV}(\%)$ & 11,84 & 51,29 & 26,39 & 15,06 & 11,36 \\
\hline
\end{tabular}

Médias seguidas por letras distintas, na mesma coluna, diferem significativamente entre si, pelo teste de Tukey, a $5 \%$ de probabilidade. * significativo ao nível de $5 \%$ de probabilidade; ** significativo ao nível de $1 \%$ de probabilidade; ns não significativo.

de enraizamento ( 78,13 a 93,75\%) obtidos neste trabalho, que foi conduzido entre meados de setembro a meados de novembro, são bem superiores aos obtidos por Nachtigal et al. (1999), que obtiveram 36,8\% como melhor resultado, no início de março a meados de maio. Este fato indica que a época do ano pode influenciar no enraizamento e que, no caso da estaquia herbácea, os melhores resultados são obtidos na época de maior crescimento vegetativo (primavera-verão), segundo Hartmann et al. (1997). Na Tailândia, Suriyapananont (1990) verificou que para o umezeiro, os melhores resultados foram obtidos nos meses de junho e outubro, enquanto os meses de abril e agosto foram os piores. Segundo Zhang \& Masaki (1994), a porcentagem de enraizamento no umezeiro está negativamente correlacionada com o teor de açúcares totais e positivamente com o conteúdo de amido das estacas.

Para as variáveis porcentagem de calo, raízes por estaca, comprimento de raízes e porcentagem de estacas brotadas, não foi observada diferença significativa entre os clones testados. Ao observarmos o número de raízes por estaca (que variou de $6,71$ a 7,82$)$ e o comprimento das raízes $(7,22$ a $8,37 \mathrm{~cm})$, verifica-se uma capacidade de emissão de raízes e vigor satisfatórios para esta espécie, com a utilização de estacas herbáceas coletadas na primavera. A elevada porcentagem de estacas brotadas, com valores próximos a $85,0 \%$, também contribui para o sucesso deste método, pois, desta forma, o processo fotossintético não é interrompido, e a estaca enraizada passará a sintetizar seu próprio alimento (Reuveni \& Raviv, 1981). A maior porcentagem de estacas mortas foi verificada no Clone 02 , ainda assim menor que $10 \%$ e considerada muito baixa.

A utilização do AIB a 2000mg. $\mathrm{L}^{-1}$ foi altamente benéfica para aumentar a porcentagem de enraizamento das estacas (Tabela 2). Estes resultados também estão de acordo com Nachtigal et al. (1999), que testaram seu efeito para estacas herbáceas, e com Miranda et al. (2000), que o utilizaram em estacas lenhosas de umezeiro. Suriyapananont (1990), estudando diferentes reguladores de crescimento na propagação do umezeiro, comprovou que o AIB aumentou o enraizamento nas concentrações entre 1500 e $3000 \mathrm{mg} . \mathrm{L}^{-1}$; entretanto, a concentração de $2000 \mathrm{mg} \cdot \mathrm{L}^{-1}$ foi significativamente superior aos demais reguladores e concentrações testadas, obtendo $56,8 \%$ de enraizamento. O efeito benéfico do AIB no enraizamento de estacas foi também observado para estacas lenhosas e semilenhosas de cultivares-copa de pessegueiro (Fachinello et al., 1981, 1982 e 1984).

Em função da elevada porcentagem de enraizamento observada nos tratamentos com o AIB, a porcentagem de calo foi muito baixa, como se pode observar na Tabela 2. Das 320 estacas tratadas com o regulador de crescimento, apenas 2 formaram exclusivamente calo $(0,63 \%)$. A formação de calo e de raízes são processos independentes para a maioria das plantas. A ocorrência simultânea é devido a condições internas e ambientais semelhantes. Entretanto, para algumas plantas, a formação de calo pode ser precursora da formação de raízes (Hartmann et al., 1997). 
O AIB ainda favoreceu a emissão de um maior número de raízes adventícias por estaca $(11,28)$ e com maior comprimento $(8,27 \mathrm{~cm})$. Estes resultados estão em concordância com Nachtigal et al. (1999) apenas para a variável número de raízes. Em estacas lenhosas de umezeiro, a concentração de $2000 \mathrm{mg} . \mathrm{L}^{-1}$ de AIB também proporcionou um aumento do número e comprimento de raízes (Miranda et al., 2000). As porcentagens de estacas brotadas obtidas com as concentrações de 0 e $2000 \mathrm{mg} . \mathrm{L}^{-1}$ de AIB foram de $85,63 \%$ e $84,38 \%$, respectivamente, demonstrando que o regulador não exerceu influência sobre esta variável. Não houve efeito significativo da interação Clone x AIB nas variáveis analisadas (Tabela 2), demonstrando que os fatores estudados agem de forma independente.

\section{CONCLUSÕES}

1. A propagação vegetativa do umezeiro por estacas herbáceas obtidas na primavera é viável em câmara de nebulização.

2. A maior porcentagem de enraizamento foi observada nas estacas provenientes do Clone 15, que foi significativamente superior ao Clone 02 , sendo que os Clones 05 e 10 se comportaram como intermediários.

3. O ácido indolbutírico, na concentração de $2000 \mathrm{mg}$.L ${ }^{1}$, beneficiou o enraizamento das estacas, favoreceu a emissão de um maior número de raízes adventícias por estaca e aumentou o comprimento de raízes. O AIB não influenciou na brotação das estacas.

\section{REFERÊNCIAS BIBLIOGRÁFICAS}

CAMPO DALL'ORTO, F.A.; OJIMA, M.; BARBOSA, W.; MARTINS, F.P. O nanismo do pessegueiro induzido pela enxertia no damasqueiro-japonês. Pesquisa Agropecuária Brasileira, Brasília, v.27, n.3, p.517-521, 1992.

CAMPO DALL'ORTO, F.A.; BARBOSA, W.; OJIMA, M.; MARTINS, F.P.; FOBÉ, L.A. Comportamento de pessegueiros IAC enxertados no damasqueiro-japonês e no pessegueiro 'Okinawa'. In: CONGRESSO BRASILEIRO DE FRUTICULTURA, 13., 1994, Salvador. Anais... Cruz das Almas: SBF, 1994. v.3, p.879880.

CAMPO DALL'ORTO, F.A.; OJIMA, M.; BARBOSA, W.; MARTINS, F.P. Damasco-japonês (umê) em São Paulo: opção para o século 21. O Agronômico, Campinas, v.47/50, p.18-20, 1995/1998. (Boletim Técnico Informativo).

CAMPO DALL'ORTO, F.A.; OJIMA, M.; BARBOSA, W.; MARTINS, F.P. Damasco-japonês (umê) Prunus x Mume Sieb. \& Zucc. In: FAHL, J.I. et al. (Ed.) Instruções agrícolas para as principais culturas econômicas. 6.ed. Campinas: Instituto Agronômico, 1998.p.117-119. (Boletim Técnico, 200).

FACHINELLO, J.C.; KERSTEN, E. Efeito do ácido indolbutírico na percentagem de estacas semi-lenhosas enraizadas de pessegueiro (Prunus persica (L.) Batsch.) cv. 'Diamante', em condição de nebulização. Revista Brasileira de Fruticultura,
Recife, v.3, p.49-50, 1981.

FACHINELLO, J.C.; KERSTEN, E.; MACHADO, A.A. Efeito do ácido indolbutírico no enraizamento de estacas lenhosas de pessegueiro cv. Diamante. Pesquisa Agropecuária Brasileira, Brasília, v.17, n.2, p.247-252, 1982.

FACHINELLO, J.C.; KERSTEN, E.; SILVEIRA JÚNIOR, P. Efeito do ácido indolbutírico na porcentagem de estacas lenhosas enraizadas e na obtenção de mudas de pessegueiro (Prunus persica (L.) Batsch). In: CONGRESSO BRASILEIRO DE FRUTICULTURA, 7., 1983, Florianópolis. Anais...Cruz das Almas: SBF/EMPASC, 1984.p.1088-1096.

FACHINELLO, J.C.; HOFFMANN, A.; NACHTIGAL, J.C.; KERSTEN, E.; FORTES, G.R. de L. Propagação de plantas frutíferas de clima temperado. 2.ed. Pelotas: UFPEL, 1995.178p.

HARADA, H.; MURAI, Y. Micropropagation of Prunus mume. Plant Cell, Tissue and Organ Culture, Shizuoka, v.46, n.3, p.265267. 1996.

HARTMANN, H.T.; KESTER, D.E.; DAVIES JR., F.R.; GENEVE, R.L. Plant Propagation: Principles and Practices. 6.ed. New Jersey: Prentice-Hall, 1997. 770p.

MIRANDA, C.S. de.; HOFFMANN, A.; COELHO, G. de A.; NORBERTO, P.M.; CHALFUN, M.Z.H. Efeito do ácido indolbutírico e do substrato no enraizamento de estacas lenhosas de umezeiro (Prunus x Mume, Sieb \& Zucc.). In: CONGRESSO BRASILEIRO DE FRUTICULTURA, 16., 2000, Fortaleza. Resumos... Fortaleza: Embrapa Agroindústria Tropical/SBF, 2000.p.595.

NACHTIGAL, J.C.; PEREIRA, F.M.; CAMPO DALL'ORTO, F.A.; OJIMA, M.; MARTINS, F.P. Propagação vegetativa do umezeiro (Prunus mume) por meio de estacas herbáceas. Revista Brasileira de Fruticultura, Jaboticabal, v.21, n.2, p. 226-228, 1999.

NAKAMURA, C.H.; SCARPE FILHO, J.A.; KLUGE, R.A. Avaliação preliminar do umezeiro como porta-enxerto para pessegueiro e nectarineira. Revista Brasileira de Fruticultura, Jaboticabal, v.21, n.2, p.116-118, 1999.

REIGHARD, G.L.; CAIN, D.W.; NEWALL JR., W.C. Rooting and survival potential of hardwood cuttings of 406 species, cultivars, and hybrids of Prunus. HortScience, Alexandria, v.25, n.5, p.517$518,1990$.

REUVENI, O.; RAVIV, M. Importance of leaf retention to rooting of avocado cuttings. Journal of the American Society for Horticultural Science, Alexandria, v.106, n.2, p.127-130, 1981.

SURIYAPANANONT, V. Stem cuttings of japanese apricot as related to growth regulators, rooting media and seasonal changes. Acta Horticulturae, Wageningen, n.279, p.475-480, 1990.

ZHANG, Y.J.; MASAKI, N. Factors affecting rooting rate of greenwood cuttings of Prunus mume. Advances in Horticulturae, Hangzhou, n.1, p.431-434, 1994. 